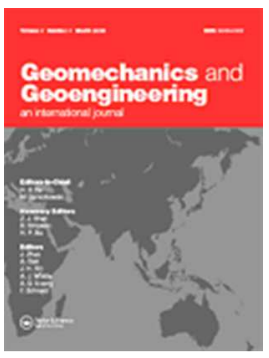

\title{
Numerical simulation of the undrained stability of slopes in anisotropic fine-grained soils
}

\begin{tabular}{|r|l|}
\hline Journal: & Geomechanics and Geoengineering: An International Journal \\
\hline Manuscript ID & Draft \\
\hline Danuscript Type: & Paper \\
\hline Complete List of Authors: & $\begin{array}{l}\text { Conesa, Sergi; Tongji University } \\
\text { Mánica, Miguel Angel; Universidad Politecnica de Catalunya, Ingeniería Civil } \\
\text { y Ambiental } \\
\text { Gens, Antonio; Universidad Politecnica de Catalunya, Ingeniería del } \\
\text { Terreno } \\
\text { Huang, Yu; Tongji University, Geotechnical Engineering }\end{array}$ \\
\hline Keywords: & \begin{tabular}{l} 
Slope stability, Fine-grained soils, Anisotropy, Undrained strength \\
\hline
\end{tabular} \\
\hline
\end{tabular}

SCHOLARONE ${ }^{m}$

Manuscripts 


\title{
Numerical simulation of the undrained stability of slopes in anisotropic fine-grained soils
}

\author{
Sergi Conesa (sergi_cb_63@hotmail.com) \\ Department of Geotechnical Engineering, College of Civil Engineering \\ Tongji University, China
}

Miguel Mánica (miguel.angel.manica@upc.edu)

Department of Civil and Environmental Engineering

Universitat Politècnica de Catalunya, Barcelona Tech, Spain

Antonio Gens (antonio.gens@upc.edu) (corresponding author)

Department of Civil and Environmental Engineering

Universitat Politècnica de Catalunya, Barcelona Tech, Spain

Yu Huang (yhuang@tongji.edu.cn)

Department of Geotechnical Engineering, College of Civil Engineering

Tongji University, China

\begin{abstract}
The undrained stability of slopes in anisotropic fine-grained soils is studied in this paper using the finite element method (FEM). A constitutive model is presented, able to account for the observed variation of undrained strength with loading direction. The model is able to encompass the different strength distributions observed in normally, slightly overconsolidated and heavily overconsolidated soils. A series of stability analyses have been performed to explore the effect of the type of undrained strength anisotropy on the stability and failure mechanisms of slopes of different inclinations. In addition, a real case study of the failure of an underwater slope is analysed with the numerical approach presented. It suggests that, by considering undrained strength anisotropy, the failure can be satisfactorily explained.
\end{abstract}


Keywords: Slope stability; fine-grained soils; anisotropy; undrained strength

\section{Introduction}

It has long been recognized that soils are generally anisotropic (Wolf 1935, Casagrande and Carrillo 1944), with some of their properties varying depending on the direction of loading (e.g. Arthur et al. 1977, Lade and Kirkgard 2000, Zdravkovic and Jardine 2000, Nishimura et al. 2007). In particular, strength anisotropy should be the main concern in relation with the stability assessment of geostructures. Nevertheless, the incorporation of this feature is rarely considered in routine slope stability analyses, in spite of the fact that its absence may lead to an overestimation of the factor of safety (FOS). To include strength anisotropy in slope stability computations two main steps are required: the first one is to stablish a failure criterion introducing a dependency with loading direction, able to account for the observed variation of strength. A number of anisotropic failure criteria for soils have been proposed; a review can be found in Mánica et al. (2016). The second step is to introduce the anisotropic criterion into an appropriate methodology for assessing the stability of slopes, such as: limit equilibrium methods, limit analyses or numerical methods. For instance, Chen et al. (1975) used the upper bound technique of limit analysis to stablish an expression for the stability number $N_{0}$, that considered the cohesion variation postulated by Casagrande and Carrillo (1944). The same cohesion variation was included in Bishop's (1955) simplified method of slices by Al-Karni and Al-Shamrani (2000). Su and Liao (1999) used limit state analysis and a total stress anisotropic strength criterion to calculate an anisotropic FOS. In addition, they provided a simplified approach that can be applied in routine analyses. Another appealing alternative is the use of numerical methods, such as the FEM, which has proved to be a reliable and robust approach for assessing the FOS of slopes (Griffiths and Lane 1999). Here, no a priori assumptions are made regarding the failure surface that is part of the solution. It is 
a very versatile tool, allowing complex geometries and material behaviour, spatial variability of properties, or even the possibility to include stabilization techniques such as piles, bolts or geo-synthetics. Therefore, the use of FEM in combination with an anisotropic constitutive law was a natural step to study the slope stability problem. An example of this approach can be found in Zdravković et al. (2002), where the anisotropic MIT soil model (Whittle and Kavvadas 1994) was employed for the simulation of a full-scale test embankment brought to failure. Another example is given by Schweiger et al. (2009), where the multilaminate framework is extended to consider inherent strength anisotropy through the microstructure tensor proposed by Pietruszczak and Mroz (2000), and the resulting constitutive model is then applied to the slope stability problem.

A prevailing conclusion in the mentioned works is that the incorporation of strength anisotropy results in a lower FOS, compared to the isotropic analysis using the strength measured with conventional tests, when loading is perpendicular to bedding. However, only the case of a monotonic decrease of the strength between the loading perpendicular and parallel to bedding is generally considered. As it will be shown in section 2, this is a typical behaviour of $K_{0}$ normally-consolidated soils. However, over-consolidated materials may exhibit a quite different behaviour, not yet properly considered in slope stability analyses.

In this paper, the undrained stability of slopes is studied using the FEM. A simple constitutive model is presented, able to account for the different variations of the undrained strength with loading direction that are discussed in section 2. The model is then employed in a series of stability analyses, whose main objective is to recognize situations where strength anisotropy will play a major role in the stability of slopes, depending on the type of strength distribution. In addition, a real case study of the failure of a $30 \mathrm{~m}$ high underwater slope at the Port of San Francisco (Duncan and Buchignani 1973) was analysed with the present numerical approach. 
The possibility of explaining the observed failure by including the undrained anisotropy of the San Francisco Bay mud is explored.

\section{Undrained strength anisotropy of fine grained-soils}

Skempton and Hutchinson (1969) indicated how the undrained strength of clays varies with the direction of loading (Figure 1). They noted that for normally- or lightly over-consolidated clays (clay from Welland, San Francisco Bay clay and clay from Surte in Figure 1) the undrained strength is highest when the specimen axis (which in turn is parallel to the major principal stress $\sigma_{1}$ ) is perpendicular to bedding, a rather intuitive result. The strength either decreases monotonically with orientation, or there is a minimum value at an intermediate angle, but with a strength just slightly lower than for loading parallel to bedding. On the other hand, heavily over-consolidated materials (London clay from Wraysbury and Ashford sites in Figure 1) exhibit a different pattern. The behaviour is similar to the normally-consolidated clays at low angles, but then the strength rises quite rapidly so that the value for loading parallel to bedding can be even higher than for loading perpendicular to bedding. Skempton and Hutchinson (1969) interpreted that these high strengths for loading parallel to bedding very probably reflect the high lateral in situ consolidation pressure $\left(K_{0}>1\right)$ in the London clay (Skempton 1961). These results suggest a progressive evolution of anisotropy with the change in over-consolidation ratio (OCR).

The behaviour for normally or lightly over-consolidated soils has been also confirmed by a series of investigations carried out with the hollow cylinder apparatus (HCA) at the Imperial College of London (Menkiti 1995, Jardine and Menkiti 1999, Zdravkovic and Jardine 2000). This device allows to study the anisotropic characteristics of soils by the rotation of the principal stresses (Hight et al. 1983). The results show a monotonic decrease of the undrained strength with the loading direction, similar to the one exhibited by the clay from Welland in 
Figure 1. In the same way, the behaviour of the natural heavily over-consolidated London clay has been verified during the investigations for the Terminal five of Heathrow Airport (Nishimura et al. 2007), where a similar trend as the Wraysbury and Ashford (Figure 1) sites was observed. Nevertheless, this pattern may be disrupted by the presence of fissures (Nishimura et al. 2007). This kind of anisotropy has also been identified in other stiff finegrained materials. For instance, tests carried out on shale rocks have also shown this strength behaviour (McLamore and Gray 1967, Niandou et al. 1997, Cho et al. 2012), and a compilation of data by Sayers (2013) suggest that the stiffness is also higher in shale rocks when loading is oriented parallel to bedding. Similar conclusions can be drawn about the Opalinus clay sampled at the Mont Terri underground laboratory (Naumann et al. 2007).

It is not clear if the loading history resulting in over-consolidation can explain by itself the observed evolution of anisotropy, or if a more complex interaction of phenomena (including sedimentation, gravitational compaction, unloading and cementation) are the origin of the observed behaviour; more research is needed in this regard. Nevertheless, it seems that it is possible to classify the undrained strength anisotropy of fine-grained soils in three types as shown in Figure 2. The convention employed to define the direction of anisotropy with respect to the loading is also depicted in the figure, and will be followed in the entire document. $\delta$ corresponds to the angle between the normal to bedding and the direction of the applied major principal stress. Therefore $\delta=0^{\circ}$ and $\delta=90^{\circ}$ correspond to the major principal stress acting perpendicular and parallel to bedding respectively. In addition, $\Omega$ is defined as,

$$
\Omega(\delta)=\frac{S_{\mathrm{u}}(\delta)}{S_{\mathrm{u}}(0)}
$$

The first strength distribution in Figure 2 corresponds to a monotonic decrease of the strength between $\delta=0^{\circ}$ and $\delta=90^{\circ}$. In the other two, the minimum strength is found at an 
intermediate orientation, but in the second type $\Omega(90) \leq \Omega(0)$, while in the third one $\Omega(90)>\Omega(0)$. A constitutive model able to incorporate these strength distributions is presented in the following section.

\section{Cross-anisotropic constitutive model}

The soil mechanics convention (compression stress and strains are positive) is employed and will be followed in the entire document. Only cross-anisotropy (or transverse isotropy) is considered, and therefore the existence of a plane where properties are the same in all directions. This generally corresponds to the bedding planes in sedimentary materials and will be referred to as the isotropic plane. The model is formulated within the framework of elasto-plasticity. Details about this theory are not given here and can be found elsewhere (e.g. Simo and Hughes 1998). Only the classical expression relating stress and strain increments for the elastic perfectly plastic case is presented in Eq. (2).

$$
\mathrm{d} \boldsymbol{\sigma}=\left(\mathbf{D}_{\mathrm{e}}-\frac{\mathbf{D}_{\mathrm{e}}(\partial g / \partial \boldsymbol{\sigma})(\partial f / \partial \boldsymbol{\sigma})^{\mathrm{T}} \mathbf{D}_{\mathrm{e}}}{(\partial f / \partial \boldsymbol{\sigma})^{\mathrm{T}} \mathbf{D}_{\mathrm{e}}(\partial g / \partial \boldsymbol{\sigma})}\right) \mathrm{d} \boldsymbol{\varepsilon}=\mathbf{D}_{\mathrm{ep}} \mathrm{d} \boldsymbol{\varepsilon}
$$

where $\boldsymbol{\sigma}$ is the column matrix of independent stress components, $\boldsymbol{\varepsilon}$ is the column matrix of engineering strain components, $f$ is the yield function bounding the elastic domain, $g$ is the plastic potential function describing the direction of plastic flow, $\mathbf{D}_{\mathrm{e}}$ is the elastic stiffness matrix, and $\mathbf{D}_{\text {ep }}$ is the elasto-plastic stiffness matrix.

Inside the yield surface the response is assumed linear elastic, characterized by Hooke's law. The yield function is based on the Mohr-Coulomb criterion, which for the isotropic case can be expressed in the following way, 


$$
f=\left(\cos \theta+\frac{1}{\sqrt{3}} \sin \phi \sin \theta\right) J-p \sin \phi-c \cos \phi
$$

where $\phi$ is the friction angle, $c$ is the cohesion, $p$ is the mean stress, $J=\sqrt{J_{2}}$ where $J_{2}$ is the second invariant of the deviatoric stress tensor $\mathbf{s}$, and $\theta$ is the Lode's angle. However, in the present research only the problem of undrained stability of slopes is addressed, and therefore $\phi=0^{\circ}$ and $c=S_{u}$ are assumed. In this case Eq. (3) reduces to,

$$
f=J \cos \theta-S_{u}
$$

corresponding to the Tresca yield function. However, Eq. (4) present corners singularities where gradients are not defined; they were smoothed following the Sloan and Booker (1986) procedure. In addition, an associated flow rule is considered in the octahedral plane.

The anisotropic extension of the model is obtained replacing $S_{\mathrm{u}}$ in Eq. (4) by,

$$
S_{\mathrm{u}}^{*}=\Omega(\delta) S_{\mathrm{u}}(0)
$$

In this way, a dependency of the strength with the loading direction is introduced. If $\mathbf{n}$ is the vector normal to the isotropic plane, and $\mathbf{v}$ is the direction of the major principal stress, then $\delta$ can be defined by,

$$
\delta=\cos ^{-1} \frac{|\mathbf{n} \cdot \mathbf{v}|}{|\mathbf{n}| \cdot|\mathbf{v}|}
$$

The direction of $\mathbf{n}$ accounts for situations where the isotropic plane is not horizontal with respect to the global coordinate system. In a three-dimensional (3D) analysis, where the $z$ axis stands for the depth, the orientation of the isotropic plane can be described according to Figure 3a, with $\mathbf{n}$ given by, 


$$
\mathbf{n}=\left[\begin{array}{c}
\sin \beta \sin \alpha \\
-\cos \alpha \sin \beta \\
\cos \beta
\end{array}\right]
$$

In a two-dimensional (2D) analysis, where the $y$ axis stands for the depth, and the orientation of the isotropic plane is assumed to vary only around the direction perpendicular to the analysis plane, $\mathbf{n}$ is defined by Eq. (8) (Figure 3b).

$$
\mathbf{n}=\left[\begin{array}{c}
-\sin \alpha \\
\cos \alpha \\
0
\end{array}\right]
$$

For the definition of $\mathbf{v}$ the eigenproblem must be solved for the stress tensor. In the present model this is performed numerically using the Jacobi method (Press et al. 1992).

A function is employed to represent $\Omega$, flexible enough to accommodate the types of strength distributions identified in Figure 2. This was achieved by deriving $\Omega$ from the combination of a sigmoid function and its derivative, the first one accounting for the monotonic change of strength between $\delta=0^{\circ}$ and $\delta=90^{\circ}$, and the second one accounting for a possible minimum strength at an intermediate orientation. In this way, $\Omega$ is defined as,

$$
\Omega=\frac{A \mathrm{e}^{\left(\delta_{m}-\delta\right) n}}{\left[1+\mathrm{e}^{\left(\delta_{m}-\delta\right) n}\right]^{2}}+\frac{B}{1+\mathrm{e}^{\left(\delta_{m}-\delta\right) n}}+C
$$

where, 


$$
\begin{gathered}
A=\frac{2\left(e_{1}+1\right)\left(e_{2}+1\right)\left(e_{1}-e_{2}+\Omega_{90}+e_{1} e_{2}+e_{1} \Omega_{90}-e_{2} \Omega_{90}-2 e_{1} \Omega_{m}+2 e_{2} \Omega_{m}-e_{1} e_{2} \Omega_{90}-1\right)}{\left(e_{1}-e_{2}\right)\left(e_{1}-1\right)\left(e_{2}-1\right)} \\
B=\frac{\Omega_{90}-\frac{A e_{1}}{\left(e_{1}+1\right)^{2}}+\frac{A e_{2}}{\left(e_{2}+1\right)^{2}}-1}{\frac{1}{e_{1}+1}-\frac{1}{e_{2}+1}} \\
C=1-\frac{A e_{2}}{\left(e_{2}+1\right)^{2}}-\frac{B}{e_{2}+1} \\
e_{1}=\mathrm{e}^{n\left(\delta_{m}-90\right)} \\
e_{2}=\mathrm{e}^{n \delta_{m}}
\end{gathered}
$$

and $\Omega_{90}=S_{\mathrm{u}}(90) / S_{\mathrm{u}}(0), \Omega_{m}=S_{\mathrm{u}}\left(\delta_{m}\right) / S_{\mathrm{u}}(0), \delta_{m}$ is the orientation at which the centre of the sigmoid function and its derivative occur, and $n$ is a constant controlling the curvature of the function. The graphical interpretation of these parameters with respect to the function $\Omega$ is depicted in Figure 4. It is important to mention that the minimum value of $\Omega$ does not necessarily occur at $\delta_{m}$, and it was not explicitly included in Eq. (9). Nevertheless, for a given set of parameters it can be computed as,

$$
\delta_{\text {min }}=\delta_{m}-\frac{\ln \left(\frac{A-B}{A+B}\right)}{n}
$$

The effect of either the sigmoid function or its derivative can be removed from $\Omega$ if desired. For instance, if only a monotonic decrease of the strength is sought between $\delta=0^{\circ}$ and $\delta=90^{\circ}$, then $\delta_{m}$ must be equal to $45^{\circ}$ and $\Omega_{m}$ equal to $\left(1+\Omega_{90}\right) / 2$. In this case the effect of the sigmoid derivative is deactivated and only $\Omega_{90}$ and $n$ are required to define $\Omega$. On the other hand, if $S_{\mathrm{u}}(0) \approx S_{\mathrm{u}}(90)$ but there is a minimum value at an intermediate orientation, then the effect of the sigmoid function can be removed by assuming $\Omega_{90}=1$. 
The gradients of the yield function $\partial f / \partial \boldsymbol{\sigma}$ in Eq. (2) can be obtained in terms of the employed stress invariants in the following way,

$$
\frac{\partial f}{\partial \boldsymbol{\sigma}}=\frac{\partial f}{\partial J} \frac{\partial J}{\partial \boldsymbol{\sigma}}+\frac{\partial f}{\partial \theta} \frac{\partial \theta}{\partial \boldsymbol{\sigma}}+\frac{\partial f}{\partial S_{\mathrm{u}}^{*}} \frac{\partial S_{\mathrm{u}}^{*}}{\partial \boldsymbol{\sigma}}
$$

where an additional term appears with respect to the standard definition, since now the undrained strength also depends on stresses. However, this last term involves the computation of $\partial \mathbf{v} / \partial \boldsymbol{\sigma}$, a task that is generally not trivial, requiring special algorithms (e.g. Nelson 1976, Mills-Curran 1988). In the present model this was simplified by defining,

$$
\frac{\partial S_{\mathrm{u}}^{*}}{\partial \boldsymbol{\sigma}}=S_{\mathrm{u}}(0) \frac{\partial \Omega}{\partial \boldsymbol{\sigma}}
$$

and approximating $\partial \Omega / \delta \boldsymbol{\sigma}$ numerically using the central difference method. In the absence of relevant data, the plastic potential was assumed isotropic.

\section{Application to slope stability analysis}

A series of finite element analyses were performed using the constitutive model described in the previous section, to assess the influence of inherent strength anisotropy on the undrained stability of slopes in fine-grained soils. Three different materials reported in the literature were considered, showing the different types of strength distributions previously defined. The main objective of these analyses is to identify situations where strength anisotropy will play a major role in the stability of the slopes depending on the type of strength distribution.

\subsection{Considered materials}

The first material corresponds to the Boston blue clay, an illitic low-plasticity marine clay deposited in the Boston basin during the Pleistocene. Engineering properties of this soil have been extensively studied in the past (Ladd and Varallyay 1965, Baligh and Levadoux 1986, Seah 1990, Sheahan et al. 1996). Here we refer to a particular set of results reported by Seah 
(1990), where the directional shear cell (DSC) (Arthur et al. 1977) was employed to study the undrained strength anisotropy in $K_{0}$ normally-consolidated specimens. As in the HCA, the DSC allows the study of anisotropy by shearing the sample with different orientations of the major principal stresses. The reported strength distribution (normalized with respect to the strength for $\delta=0^{\circ}$ ) is depicted in Figure 5. A type I distribution can be clearly identified, where a monotonic decrease of the strength is observed between $\delta=0^{\circ}$ and $\delta=90^{\circ}$, characteristic of normally-consolidated materials. Therefore, only the effect of the sigmoid function is sufficient to adjust the laboratory data, using only $\Omega_{90}$ and $n$. The adjusted function is also shown in Figure 5, the parameters are given in Table 1.

The second material corresponds to a low plasticity Alaskan silt reported by Fleming and Duncan (1990), retrieved from an offshore site in the Beaufort Sea. The samples were reconstituted from a slurry in a one-dimensional consolidometer under a given vertical pressure. The load was then removed to obtained cylindrical blocks of soil $127 \mathrm{~mm}$ in diameter and typically 102 to $127 \mathrm{~mm}$ height, from which the $35 \mathrm{~mm}$ in diameter triaxial samples were trimmed. Then a series of unconsolidated-undrained triaxial (UU) tests were performed with specimens trimmed with different orientations with respect to bedding. The normalized undrained strength is shown in Figure 5, together with the adjusted function. This corresponds to a type II distribution (Figure 2).

The third material corresponds to the natural highly over-consolidated London clay at the site of the Heathrow Airport Terminal Five. The London clay is another example of a material whose mechanical properties have been extensively studied in the past (Bishop et al. 1965, Ward et al. 1965, Hight et al. 2007). Here we refer to a set of data from the study by Nishimura et al. (2007). Figure 5 shows the normalized undrained strength variation of samples retrieved from $10.5 \mathrm{~m}$ below ground level, and with an OCR estimated around 9-12 (Nishimura et al. 2007). It corresponds to a type III distribution, which seems to be associated 
with highly over-consolidated fine-grained soils. The adjusted function is also depicted in the figure.

\subsection{Main features of the numerical models}

The considered geometry and main boundary conditions are illustrated in Figure 6. They correspond to a 2D slope of height $H$ in homogeneous soil, with the firm ground located at a distance $H$ from the toe. Different slope angles $\theta$ and different orientations of the isotropic plane $\alpha$ were employed in the analyses. These were carried out using the finite element code Plaxis (Brinkgreve et al. 2017), where the model described in section 3 was implemented as a user defined soil model. As an example, one of the employed finite element meshes (for the case with $\theta=30^{\circ}$ ) is depicted in Figure 6. It comprises 1065 triangular 15-noded finite elements with fourth-order interpolation and 12 integration points. Plane strain conditions were considered and the analyses were performed in terms of total stresses and undrained strengths. The strength reduction method was employed to determine the failure condition, as described by Griffiths and Lane (1999), where the FOS is defined as,

$$
\mathrm{FOS}=\frac{S_{\mathrm{u}}}{S_{\mathrm{u}-\mathrm{f}}}
$$

where $S_{\mathrm{u}-\mathrm{f}}$ is the undrained strength at which failure occurs. To allow direct comparison, the results were then normalized in terms of the stability number $N_{0}$, defined here as,

$$
N_{0}=\frac{\operatorname{FOS} \gamma H}{S_{\mathrm{u}}}
$$

where $\gamma$ is the unit weight of the soil.

All analyses were first performed without considering anisotropy and the results were compared with Taylor's (1937) solution, in order to validate the present numerical approach. The strength distributions in Figure 5 were then included to assess their effect on the stability 
analysis. In those cases, $S_{\mathrm{u}}$ and $S_{\mathrm{u}-\mathrm{f}}$ of Eq. (18) and (19) correspond to the values for $\delta=0^{\circ}$

The variations of the failure mechanism are also reported. They are represented by a continuous single line describing the failure plane of the mobilized mechanism. Figure 7 shows an example of a slope failure in terms of the deformed mesh (Figure 7a) and in terms of the incremental total displacement field (Figure $7 \mathrm{~b}$ ). The dashed line representing this mechanism is drawn at the centre of the zone where a high displacement gradient occurs (Figure $7 \mathrm{~b}$ ), separating the standing part of the ground and the sliding mass.

\subsection{Obtained results}

The stability numbers obtained for different inclinations of the slope are shown in Figure 8. Here the orientation of the isotropic plane was assumed horizontal. The solid and dashed black lines represent the isotropic case obtained from the numerical simulation and from Taylor's (1937) solution respectively. A good agreement between both can be noted, validating the employed numerical approach for the slope stability analysis. The other lines correspond to the anisotropic materials, whose strength distributions were shown in Figure 5. The variation of $N_{0}$ with the slope inclination $\theta$ has a similar trend for the isotropic and anisotropic cases, although the magnitude is considerably different. The Boston blue clay lies at the bottom of the graph as the most unfavourable condition, whilst the London clay shows $N_{0}$ values even higher than the isotropic case for $\theta$ values lower than $50^{\circ}$. For higher inclinations, the London clay and the isotropic case are quite similar. The Alaskan silt is found in-between the isotropic and the Boston clay cases. An important observation is that the effect of anisotropy tends to reduce with $\theta$, so that in the case of a vertical cut $\left(\theta=90^{\circ}\right)$, the effect of anisotropy becomes quite small. The same outcome has been reported by AlKarni and Al-Shamrani (2000). 
The failure mechanisms obtained for different slope inclinations are shown in Figure 9. As expected, for $\theta=15^{\circ}$ and $\theta=30^{\circ}$ a well-defined base failure is identified for the isotropic analyses. It can be noted that, despite the fact that in those inclinations the effect of anisotropy on stability number is the highest (see Figure 8), it has little effect on the failure mechanism. Only the exit point of the sliding mass for $\theta=30^{\circ}$ occurs closer to the toe for London Clay and further away in the Boston clay. The isotropic analysis with $\theta=50^{\circ}$ represents a transition between a base and a toe failure. Here we can observe that in the London clay the failure mechanism already corresponds to a toe failure, while for Boston clay and Alaskan silt the base mechanism persists. For the case with $\theta=70^{\circ}$; the isotropic case now clearly forms a toe failure, while in the Boston clay case a base mechanism still persists. The Alaskan silt shows an intermediate surface, but it is now closer to a toe mechanism. Finally, with $\theta=90^{\circ}$ all materials have moved to a toe mechanism, with a nearly planar slip surface. It can be concluded that the type of anisotropy affects the type failure for intermediate slope angles.

By examining the direction of the major principal stress along the failure surfaces, the decrease of the effect of anisotropy with $\theta$ becomes evident. This is shown in Figure 10 for the isotropic case with $\theta=15^{\circ}$ and $\theta=90^{\circ}$. For a base type mechanism, the major principal stress direction varies gradually along the failure surface from the sub-vertical to the subhorizontal orientations (from right to left in Figure 10). On the other hand, in a toe failure, the major principal stress barely deviates from the sub-vertical orientation, this corresponding to very low values of $\delta$ (for this case where $\alpha=0$ ), where the strength is quite similar for all the considered strength distributions (see Figure 5).

The relative orientation between the major principal stress and the normal to the failure surface was found to be roughly equal to $45^{\circ}$ throughout the surface, and in all performed calculations. Therefore, it coincides with Roscoe's (1970) solution $\left(45^{\circ}+\psi / 2\right)$ (Potts et al. 
1997, Mánica et al. 2018), since the employed plastic potential yields null volumetric plastic strains at failure, and therefore the dilatancy angle is $\psi=0^{\circ}$.

An additional set of analyses was performed for the case with $\theta=30^{\circ}$, but with different bedding orientations $\alpha$. Although less frequent, this condition may occur in nature due to cross-bedding or post-depositional deformations. The obtained values of $N_{0}$ and the obtained failure mechanisms are depicted in Figure 11 and Figure 12 respectively. Values of $0<\alpha<90$ correspond to dip slopes, while $90<\alpha<180$ correspond to anti-dip slopes. In this case, the failure mechanism is not particularly dependent on variations of the bedding orientation. On the other hand, $N_{0}$ is significantly affected. The Boston clay shows a wavelike behaviour, with the trough around $55^{\circ}$ in the dip slope range, and the crest around $145^{\circ}$ in the anti-dip slope range. The Alaskan silt shows a similar behaviour as the Boston clay in the dip slope range (but with higher values of $N_{0}$ ), although in the anti-dip slope zone just a slightly increase of $N_{0}$ is noticed. On the other hand, London clay shows an opposite behaviour to Boston clay, except for a point near $45^{\circ}$, where $N_{0}$ momentarily decreases. The observed behaviour can be clarified by reference to Figure 13 where the mean value of $\delta$ along the corresponding failure surface is shown. A very similar variation is obtained in the three materials. The high values of the mean $\delta$ in the dip slope range are associated with low strengths for the Boston clay and the Alaskan silt, but with high strengths for the London clay (see Figure 5). On the other hand, for lower values of $\delta$, the strength of the three materials is similar, and therefore the value of $N_{0}$ tends to be the similar for all them near the bedding orientation corresponding to the lowest mean $\delta$. However, the specific variation of $N_{0}$ with $\alpha$ is related to the particular strength distribution adopted.

\section{Underwater slope failure in San Francisco bay mud}


In addition to the synthetic cases presented in the previous section, a real case study was also evaluated with the intention of further stressing the importance of including strength anisotropy in our conventional stability calculations. It corresponds to the failure of a $30 \mathrm{~m}$ high underwater slope at the Port of San Francisco (Duncan and Buchignani 1973). Figure 14 shows a cross-section of the slope before failure and the position of the estimated failure surface. The original short-term design FOS was reported by Duncan and Buchignani (1973) to be 1.17 , i.e. it suggested a stable slope (although with a rather low FOS). Revised calculations were later performed with different limit equilibrium programs, confirming this FOS value (Duncan et al. 2014). Nevertheless, a few hours after the excavation of a section about $150 \mathrm{~m}$ long, a failure occurred involving a $75 \mathrm{~m}$ long portion of the trench. Later, a second failure occurred involving additional $60 \mathrm{~m}$. The discrepancies of the calculated FOS were attributed to a decrease of the undrained strength due to creep deformations (Duncan and Buchignani 1973). However, it can be argued that due to the very short time between the excavation and failure (just a few hours), significant creep processes would not have had enough time to occur and they may not be the main responsible for the failure.

Here, the possibility of explaining the observed failure by considering the undrained anisotropy of the San Francisco Bay mud is explored. First, an analysis without anisotropy was performed to compare with the original stability calculations. Figure 15 shows the employed simplified geometry of the slope, as well as the finite element mesh and boundary conditions used. The debris dike and the soil beneath it at the right of Figure 14 were not included in the analysis, since preliminary calculation showed that the failure surface tended to pass beneath the dike. In the real slope failure this did not occur, most likely because the soil beneath the debris dike would have consolidated under the weight of the dike, increasing its undrained strength. Therefore, the lateral boundary conditions at the right of the model were placed where the dike begins, preventing the failure mechanism passing under it. Due to 
the absence of seepage, it was possible to use the buoyant unit weights instead of total unit weights with external water pressures (Duncan et al. 2014). The average buoyant unit weight of the San Francisco Bay mud was reported to be $5.97 \mathrm{kN} / \mathrm{m}^{3}$ (Duncan 2000). The observed increase in the undrained strength with depth was also included in the analyses. Figure 16 shows the reported (Duncan 2000) and employed undrained strength profiles. For the anisotropic analysis, data of the undrained strength variation with the loading direction of the San Francisco Bay mud from Lade and Kirkgard (2000) were employed. These results are depicted in Figure 17 (normalized with respect to the strength for $\delta=0^{\circ}$ ), together with the adjusted function and its parameters. The strength reduction method, as described by Griffiths and Lane (1999), was again employed to derive the FOS.

Figure 18a shows the obtained FOS and failure mechanism (in terms of the incremental displacement field) for the isotropic analysis. The FOS of 1.175 confirms the original design value (Duncan and Buchignani 1973), as well as the revised calculations performed later (Duncan et al. 2014). The failure mechanism is quite similar to the real estimated failure surface (Figure 14), and it is practically identical to the critical sliding surface reported in the revised calculations. Therefore, it can be stated that this analysis is analogous to the original design calculations.

The anisotropic analysis is identical to the isotropic one, but the undrained strength distribution shown in Figure 17 was included. The obtained FOS and failure mechanism are depicted in Figure 18b. It is observed that the failure mechanism is not affected by anisotropy, but the FOS is now very close to unity, i.e. very close to an incipient failure condition. Therefore, a more realistic FOS has been obtained just by including in the analysis the undrained strength anisotropy of the San Francisco Bay mud. In the authors' opinion, this provides a more satisfying explanation for the discrepancies in the FOS than the possible decrease of the strength due to creep deformations is such a rapid failure. 


\section{Conclusions}

In this paper, the FEM was employed to study the effect of strength anisotropy on the undrained stability of slopes. For this purpose, an anisotropic constitutive model has been presented, able to reproduce the undrained strength variations with the loading direction, observed in different fine-grained soils. They include over-consolidated materials where the highest strengths are obtained when loading is parallel to bedding. A series of analysis have been performed to check the effect of anisotropy on the undrained stability of slopes. For comparison, the isotropic case with the undrained strength obtained under loading perpendicular to bedding has been taken as reference. From the analyses performed, the following conclusions can be drawn:

1) The effect of strength anisotropy decreases when the inclination of the slope increases, so that it becomes quite small in the case of vertical cuts. This occurs because in the nearly planar surface formed in the latter case, the major principal stress barely deviates from the sub-vertical orientation along the slip surface, therefore corresponding to the same strength adopted for the isotropic case. Gentler slopes result in deeper failure mechanisms, where the major principal stress continuously varies along the failure surface, from the sub-vertical to the sub-horizontal directions, and therefore the whole strength distribution is relevant.

2) For horizontal bedding, distributions I and II will always result in $N_{0}$ lower than the isotropic case. The effect of anisotropy seems negligible for the type III when $\theta>50^{\circ}$, and for lower inclinations $N_{0}$ values even higher than the isotropic case can be obtained. Therefore, an isotropic analysis using the strength under loading perpendicular to bedding should be conservative in the latter case. Nevertheless, special care must be paid in the presence of pre-existing fissures, since the strength distribution obtained from a 
non-fissured sample may not represent the strength of the soil mass, and therefore the FOS may be lower than the isotropic case.

3) Undrained strength anisotropy does not have a very important effect in the failure mechanism obtained. Only close to a transition between a base and a toe failure mechanisms, the strength distribution types I and II will tend towards the former, while type III strength distribution will tend towards the latter.

4) In the case of non-horizontal bedding, the strength distributions I and II always show lower $N_{0}$ values than the isotropic analysis for all bedding orientations, although the dip slopes represent a more adverse condition than the anti-dip slopes. The opposite occurs for the distribution III, and $N_{0}$ values lower than the isotropic case can be obtained for anti-dip slopes. This behaviour is related to the average loading angle $\delta$ along the failure plane, which is higher in dip-slopes than for anti-dip slopes.

Finally, a real case failure of an underwater slope was analysed with the numerical approach presented. A more realistic FOS was obtained just by including in the analysis the undrained strength anisotropy of the San Francisco Bay mud, providing a more satisfying explanation for the over estimation of the FOS in the original design calculations.

\section{References}

Al-Karni, A.A. and Al-Shamrani, M.A., 2000. Study of the effect of soil anisotropy on slope stability using method of slices. Computers and Geotechnics, 26, 83-103.

Arthur, J.R.F., Chua, K.S., and Dunstan, T., 1977. Induced anisotropy in a sand. Géotechnique, 27 (1), 13-30.

Baligh, M.M. and Levadoux, J., 1986. Consolidation after undrained piezocone penetration. II: Interpretation. Journal of Geotechnical Engineering, 112 (7), 727-745.

Bishop, A.W., 1955. The use of the slip circle in the stability analysis of slopes. Géotechnique, 5 (1), 7-17.

Bishop, A.W., Webb, D.L., and Lewin, P.I., 1965. Undisturbed samples of London clay from the Ashford Common shaft: Strength-effective stress relationships. Géotechnique, 15 (1), 1-31. 
Brinkgreve, R.B.J., Kumarswamy, S., and Swolfs, W.M., 2017. PLAXIS 2017. Users' manual. Delft, Netherlands: Plaxis bv.

Casagrande, A. and Carrillo, N., 1944. Shear failure of anisotropic materials. Journal of the Boston Society of Civil Engineers, 31, 74-87.

Chen, W.F., Snitbhan, N., and Fang, H.Y., 1975. Stability of slopes in anisotropic, nonhomogeneous soils. Canadian Geotechnical Journal, 12 (1), 146-152.

Cho, J.W., Kim, H., Jeon, S., and Min, K.B., 2012. Deformation and strength anisotropy of Asan gneiss, Boryeong shale, and Yeoncheon schist. International Journal of Rock Mechanics and Mining Sciences, 50, 158-169.

Duncan, J.M., 2000. Factors of safety and reliability in geotechnical engineering. Journal of Geotechnical and Geoenvironmental Engineering, 126 (4), 307-316.

Duncan, J.M. and Buchignani, A.L., 1973. Failure of underwater slope in San Francisco Bay. Journal of the Soil Mechanics and Foundations Division, 99 (9), 687-703.

Duncan, J.M., Wright, S.G., and Brandon, T.L., 2014. Soil strength and slope stability. 2nd ed. Wiley.

Fleming, L.N. and Duncan, J.M., 1990. Stress-deformation characteristics of Alaskan silt. Journal of Geotechnical Engineering, 116 (3), 377-393.

Griffiths, D. V. and Lane, P.A., 1999. Slope stability analysis by finite elements. Geotechnique, 49 (3), 387-403.

Hight, D.W., Gasparre, A., Nishimura, S., Minh, R.J., Jardine, R.J., and Coop, M.R., 2007. Characteristics of the London Clay from the Terminal 5 site at Heathrow Airport. Géotechnique, 57 (1), 3-18.

Hight, D.W., Gens, A., and Symes, M.J., 1983. The development of a new hollow cylinder apparatus for investigating the effects of principal stress rotation in soils. Géotechnique, 33 (4), 355-383.

Jardine, R.J. and Menkiti, C.O., 1999. The undrained anisotropy of K0 consolidated sediments. In: Proceedings of the 12th European Conference on Soil Mechanics and Geotechnical Engineering. Amsterdam, 1101-1108.

Ladd, C.C. and Varallyay, J., 1965. The influence of the stress system on the behavior of saturated clays during undrained shear. Cambridge, MA.

Lade, P. V. and Kirkgard, M.M., 2000. Effects of stress rotation and changes of b-values on cross-anisotropic behaviour of natural, K0-consolidated soft clay. Soils and foundations, $40(6), 93-105$.

Mánica, M., Gens, A., Vaunat, J., and Ruiz, D.F., 2016. A cross-anisotropic formulation for elasto-plastic models. Géotechnique Letters, 6, 1-7.

Mánica, M., Gens, A., Vaunat, J., and Ruiz, D.F., 2018. Nonlocal plasticity modelling of strain localization in stiff clays. Computers and Geotechnics, submitted.

McLamore, R. and Gray, K.E., 1967. The mechanical behavior of anisotropic sedimentary rocks. Journal of Engineering for Industry-Transactions of the ASME, 89 (1), 62-73.

Menkiti, C.O., 1995. Behaviour of clay and clayey-sand, with particular reference to principal 
stress rotation. Imperial College of London.

Mills-Curran, W.C., 1988. Calculation of eigenvector derivatives for structures with repeated eigenvalues. AIAA Journal, 26 (7), 867-871.

Naumann, M., Hunsche, U., and Schulze, O., 2007. Experimental investigations on anisotropy in dilatancy, failure and creep of Opalinus Clay. Physics and Chemistry of the Earth, 32 (8-14), 889-895.

Nelson, R.B., 1976. Simplified calculation of eigenvector derivatives. AIAA Journal, 14 (9), 1201-1205.

Niandou, H., Shao, J.F., Henry, J.P., and Fourmaintraux, D., 1997. Laboratory investigation of the mechanical behaviour of Tournemire shale. International Journal of Rock Mechanics and Mining Sciences, 34 (1), 3-16.

Nishimura, S., Minh, N.A., and Jardine, R.J., 2007. Shear strength anisotropy of natural London Clay. Géotechnique, 57 (1), 49-62.

Pietruszczak, S. and Mroz, Z., 2000. Formulation of anisotropic failure criteria incorporating a microstructure tensor. Computers and Geotechnics, 26 (2), 105-112.

Potts, D.M., Kovacevic, N., and Vaughan, P.R., 1997. Delayed collapse of cut slopes in stiff clay. Géotechnique, 47 (5), 953-982.

Press, W.H., Teukolsky, S.A., Vetterling, W.T., and Flannery, B.P., 1992. Numerical Recipes in Fortran 77: The Art of Scientific Computing. Cambridge: Cambridge University Press.

Roscoe, K.H., 1970. The influence of strains in soil mechanics. Géotechnique, 20 (2), 129 170.

Sayers, C.M., 2013. The effect of anisotropy on the Young's moduli and Poisson's ratios of shales. Geophysical Prospecting, 61 (2), 416-426.

Schweiger, H.F., Scharinger, F., Wiltafsky, C., and Galavi, V., 2009. A multilaminate framework for modelling induced and inherent anisotropy of soils. Géotechnique, 59 (2), $87-101$.

Seah, T.H., 1990. Anisotropy of resedimented Boston Blue Clay. Massachusetts Institute of Technology.

Sheahan, T.C., Ladd, C.C., and Germaine, J.T., 1996. Rate-dependent undrained shear behavior of saturated clay. Journal of Geotechnical Engineering, 122 (2), 99-108.

Simo, J.C. and Hughes, T.J.R., 1998. Computational Inelasticity. New York: Springer.

Skempton, A., 1961. Horizontal stresses in an overconsolidated eocene clay. In: Proceedings of the 5th International Conference on Soil Mechanics and Fundation Engineering. Paris, 351-357.

Skempton, A.W. and Hutchinson, J.N., 1969. Stability of natural slopes and embankment foundations. In: Proceedings of the 7th international conference on soil mechanics and foundation engineering. Mexico, 291-340.

Sloan, S.W. and Booker, J.R., 1986. Removal of singularities in Tresca and Mohr-Coulomb yield functions. Communications in Applied Numerical Methods, 2, 173-179. 
$\mathrm{Su}$, S.F. and Liao, H.J., 1999. Effect of strength anisotropy on undrained slope stability in clay. Géotechnique, 49 (2), 215-230.

Taylor, D.W., 1937. Stability of earth slopes. Journal of the Boston Society of Civil Engineers, 24, 197-246.

Ward, W.H., Marsland, A., and Samuels, S.G., 1965. Properties of the London Clay at the Ashford Common Shaft: In-situ and undrained strength tests. Géotechnique, 15 (4), $321-344$.

Whittle, A.J. and Kavvadas, M.J., 1994. Formulation of MIT $\square$ E3 constitutive model for overconsolidated clays. Journal of Geotechnical Engineering, 120 (1), 173-198.

Wolf, K., 1935. Ausbreitung der kraft in der halbebene und ins halbraum bei anisotropen material. Zeitschrift für Angewandte Mathematik und Mechanik, 15, 249-254.

Zdravkovic, L. and Jardine, R.J., 2000. Undrained anisotropy of Ko-consolidated silt. Canadian Geotechnical Journal, 37, 178-200.

Zdravković, L., Potts, D.M., and Hight, D.W., 2002. The effect of strength anisotropy on the behaviour of embankments on soft ground. Géotechnique, 52 (6), 447-457.

\section{Figures captions}

Figure 1. Normalized undrained strength variation with the loading direction in soils with different OCRs (modified from Skempton and Hutchinson 1969)

Figure 2. Identified types of undrained strength distributions in fine-grained soils

Figure 3. Orientation of the isotropic plane for a) 3D and b) 2D problems

Figure 4. Function $\Omega$ and its parameters

Figure 5. Observed and computed normalized undrained strength distributions

Figure 6. Geometry and boundary conditions for the synthetic case

Figure 7. Definition of the failure mechanism

Figure 8. Variation of the stability number with slope inclination

Figure 9. Failure mechanisms obtained for different slope inclinations

Figure 10. Direction of the major principal stress along the failure surface of the isotropic analysis for two slope inclinations

Figure 11. Variation of the stability number with the direction of anisotropy

Figure 12. Obtained failure mechanisms for different directions of anisotropy

Figure 13. Mean $\delta$ value along the failure surface for different directions of anisotropy

Figure 14. Cross-section through the excavated trench at LASH Terminal after failure (modified from Duncan 2000)

Figure 15. Geometry and boundary conditions of the analysed underwater slope 
Figure 16. Undrained strength variation with depth for San Francisco bay mud at the LASH Terminal site (modified from Duncan 2000)

Figure 17. Observed (Lade and Kirkgard 2000) and computed normalized undrained strength distribution

Figure 18. Obtained failure mechanisms and factors of safety for the a) isotropic and b) anisotropic analyses

\section{Tables}

Table 1. Parameters of the adjusted strength distributions

\begin{tabular}{cccc}
\hline Parameter & $\begin{array}{c}\text { Boston blue } \\
\text { clay }\end{array}$ & $\begin{array}{c}\text { Alaskan } \\
\text { silt }\end{array}$ & $\begin{array}{c}\text { London } \\
\text { clay }\end{array}$ \\
\hline$\Omega_{90}$ & 0.56 & 0.85 & 1.53 \\
$\Omega_{m}$ & $\left(1+\Omega_{90}\right) / 2$ & 0.73 & 0.79 \\
$\delta_{m}$ & $45^{\circ}$ & $59^{\circ}$ & $52^{\circ}$ \\
$n$ & 0.08 & 0.06 & 0.11 \\
\hline
\end{tabular}




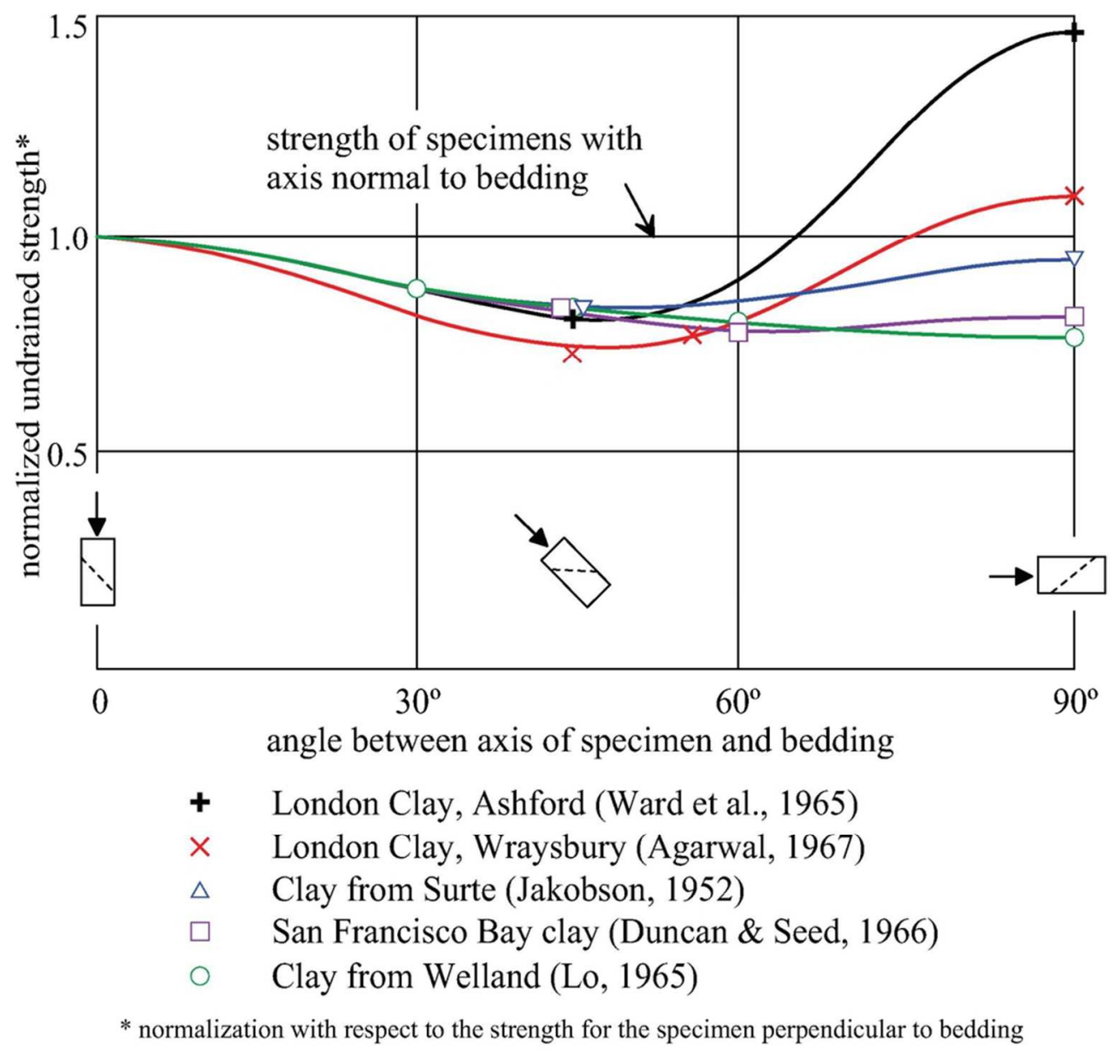

Figure 1

$86 \times 83 \mathrm{~mm}(300 \times 300$ DPI $)$ 

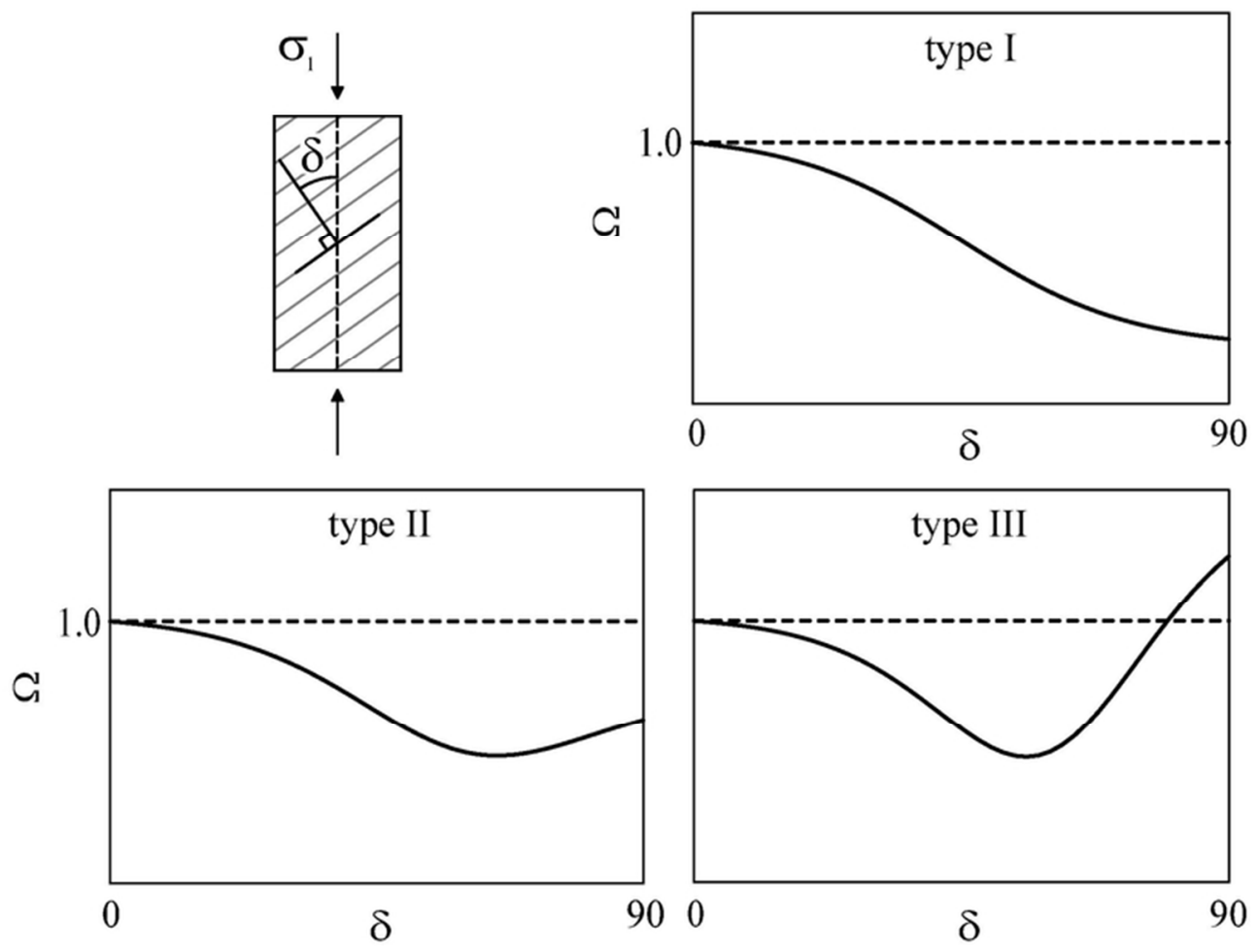

Figure2

$69 \times 53 \mathrm{~mm}(300 \times 300$ DPI $)$ 


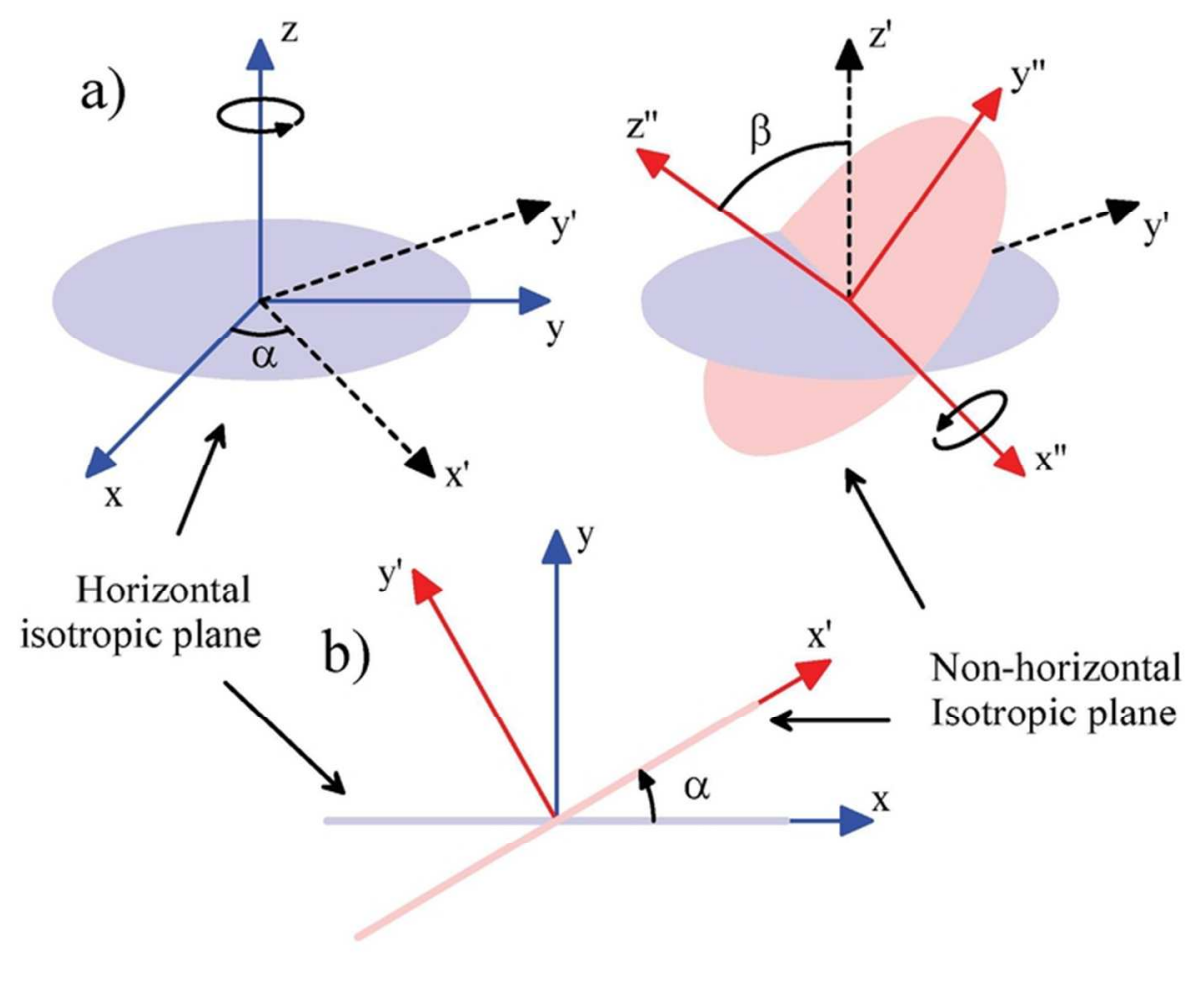

Figure 3

$69 \times 53 \mathrm{~mm}(300 \times 300 \mathrm{DPI})$ 


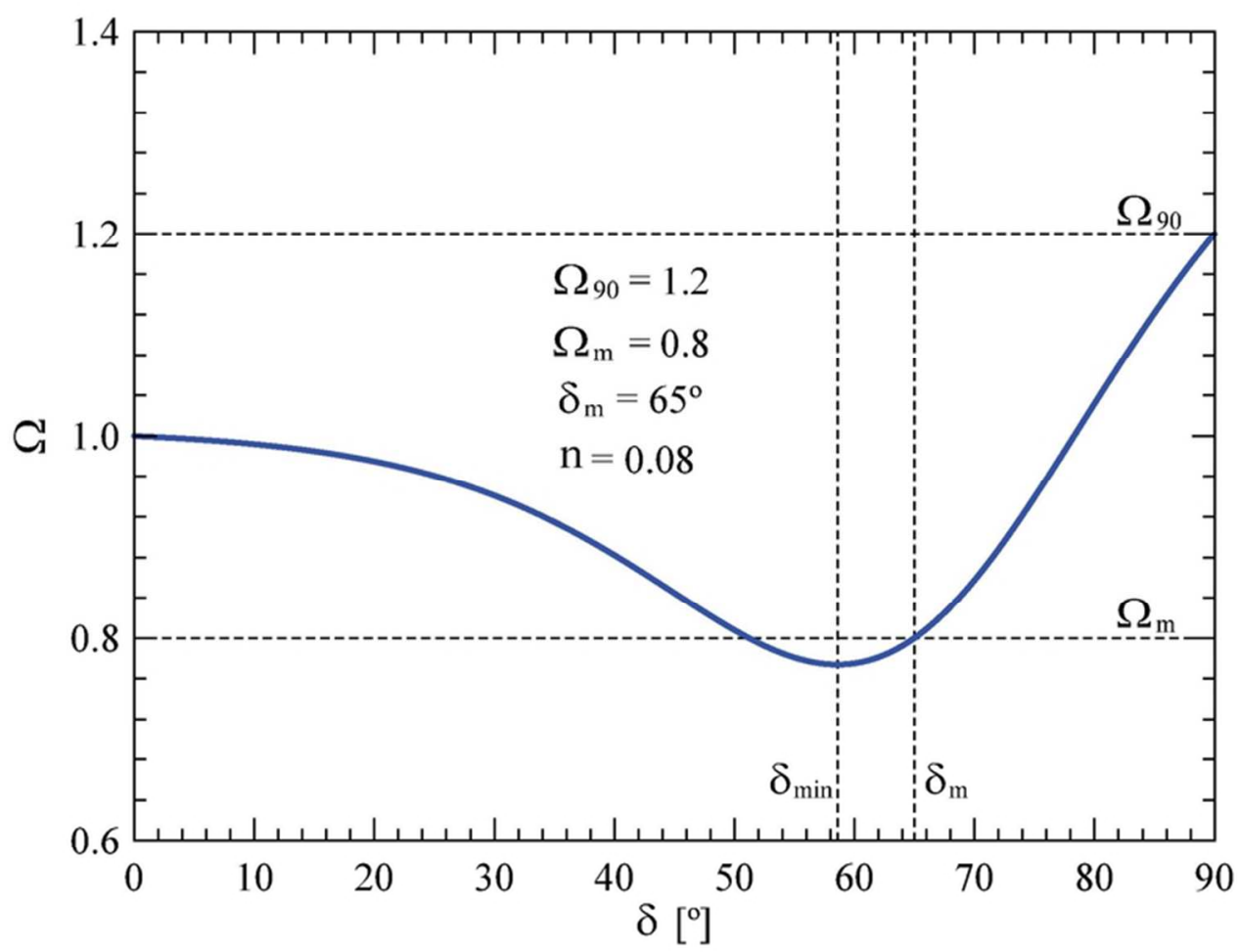

Figure 4

$69 \times 52 \mathrm{~mm}(300 \times 300$ DPI $)$ 


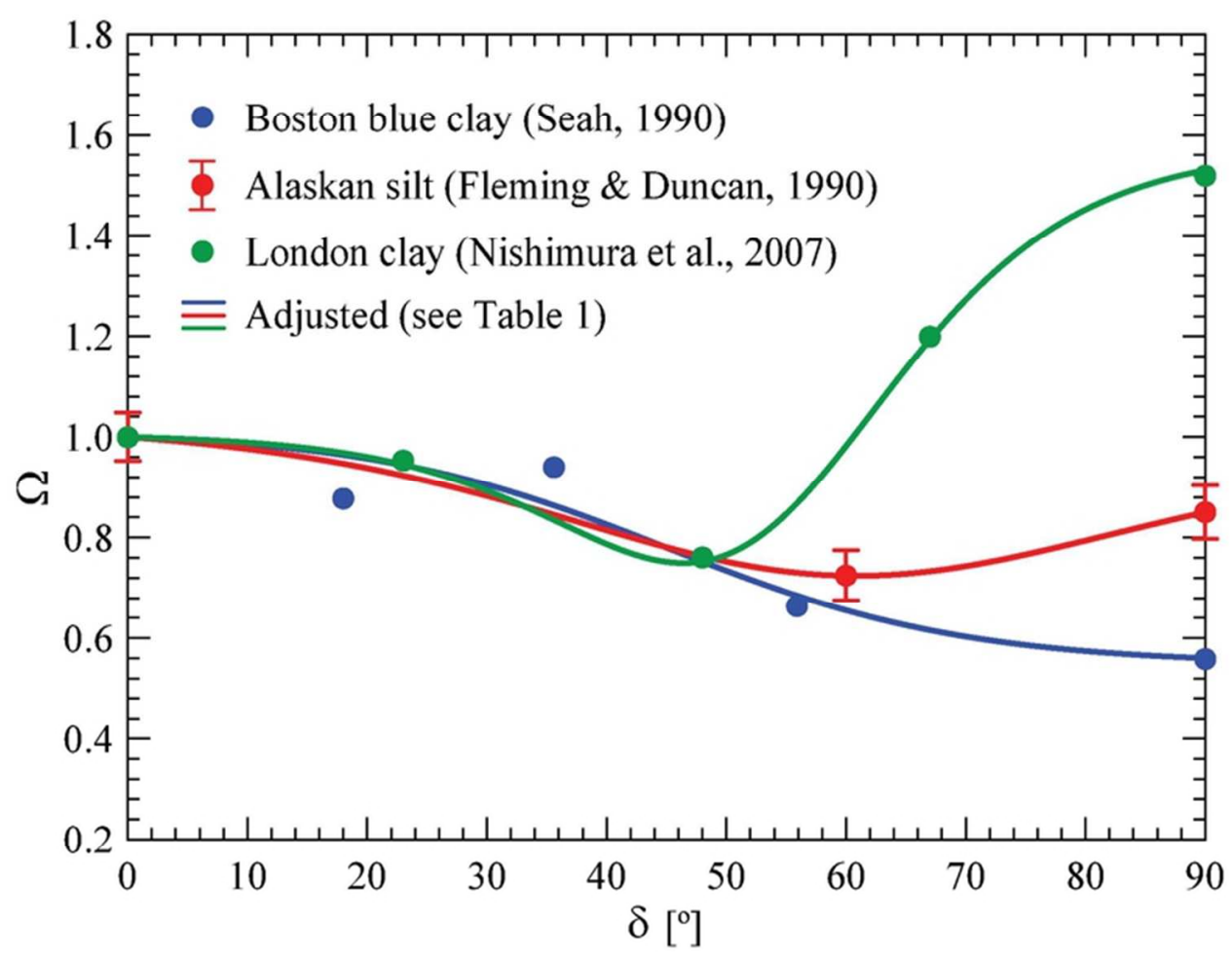

Figure 5

$69 \times 52 \mathrm{~mm}(300 \times 300$ DPI $)$ 


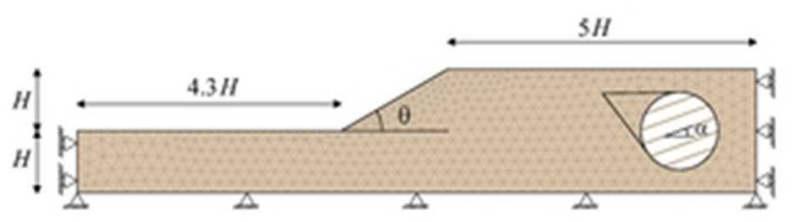

Figure 6

$25 \times 7 \mathrm{~mm}(300 \times 300$ DPI $)$

16

17

18

19

20

21

22

23

24

25

26

27

28

29

30

31

32

33

34

35

36

37

38

39

40

41

42

43

44

45

46

47

48

49

50

51

52

53

54

55

56

57

58

59

60

URL: http://mc.manuscriptcentral.com/tgeo 

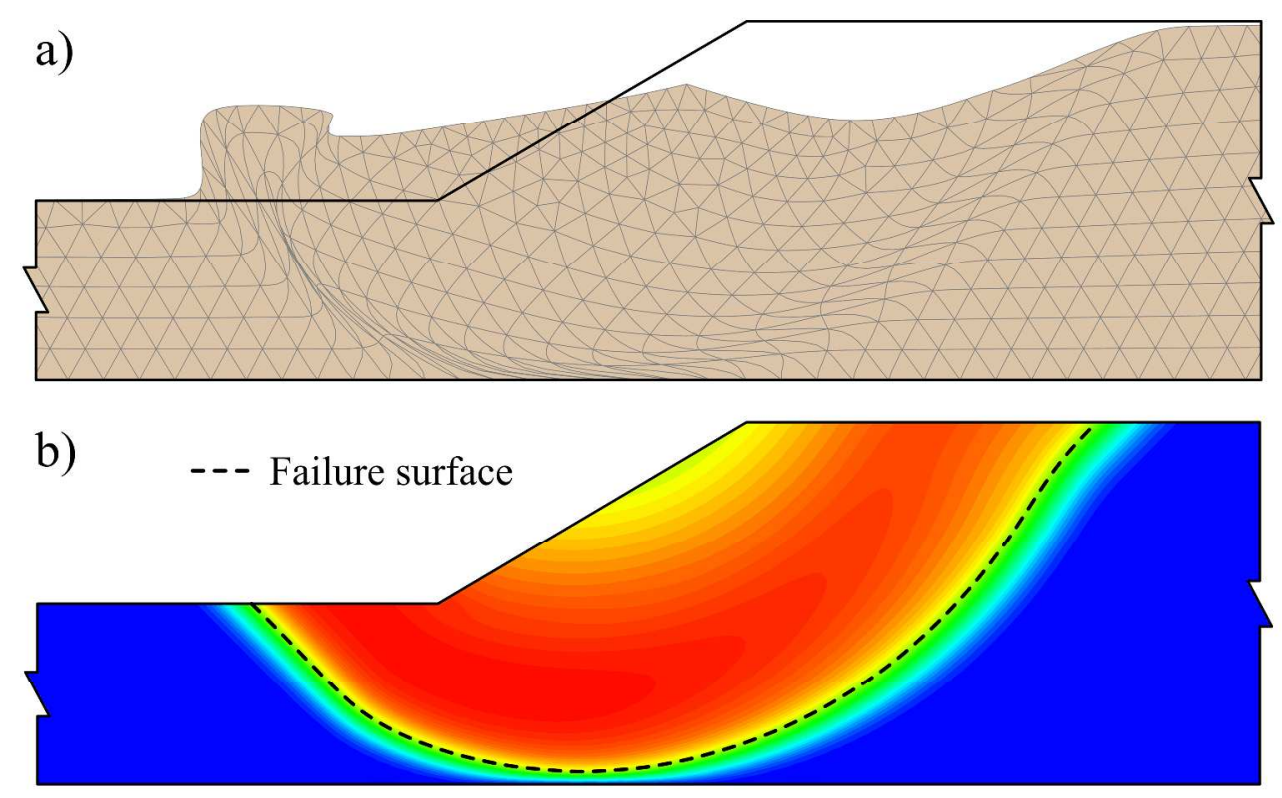

Figure 7

1499x962mm (72 x 72 DPI $)$ 


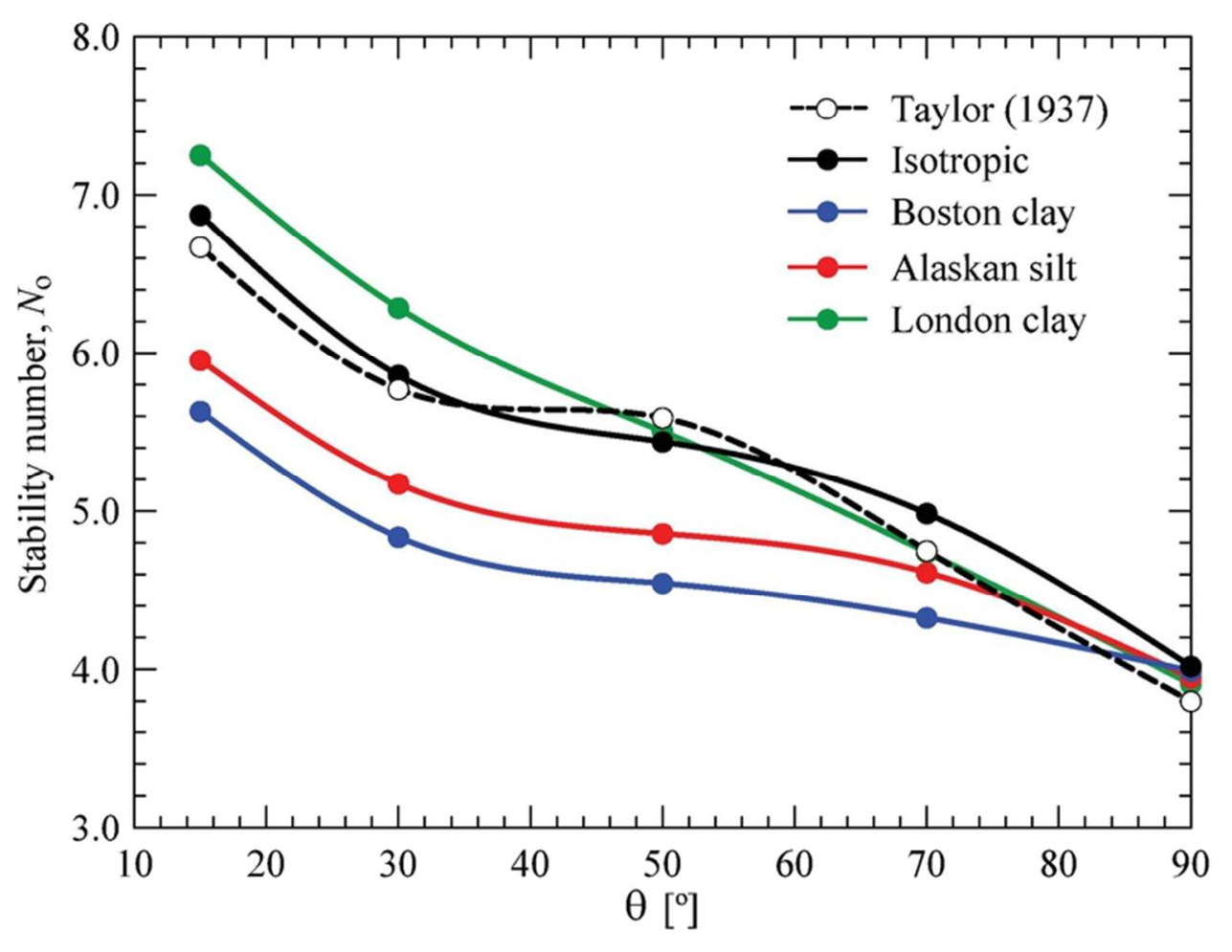

Figure 8

$69 \times 52 \mathrm{~mm}(300 \times 300 \mathrm{DPI})$ 

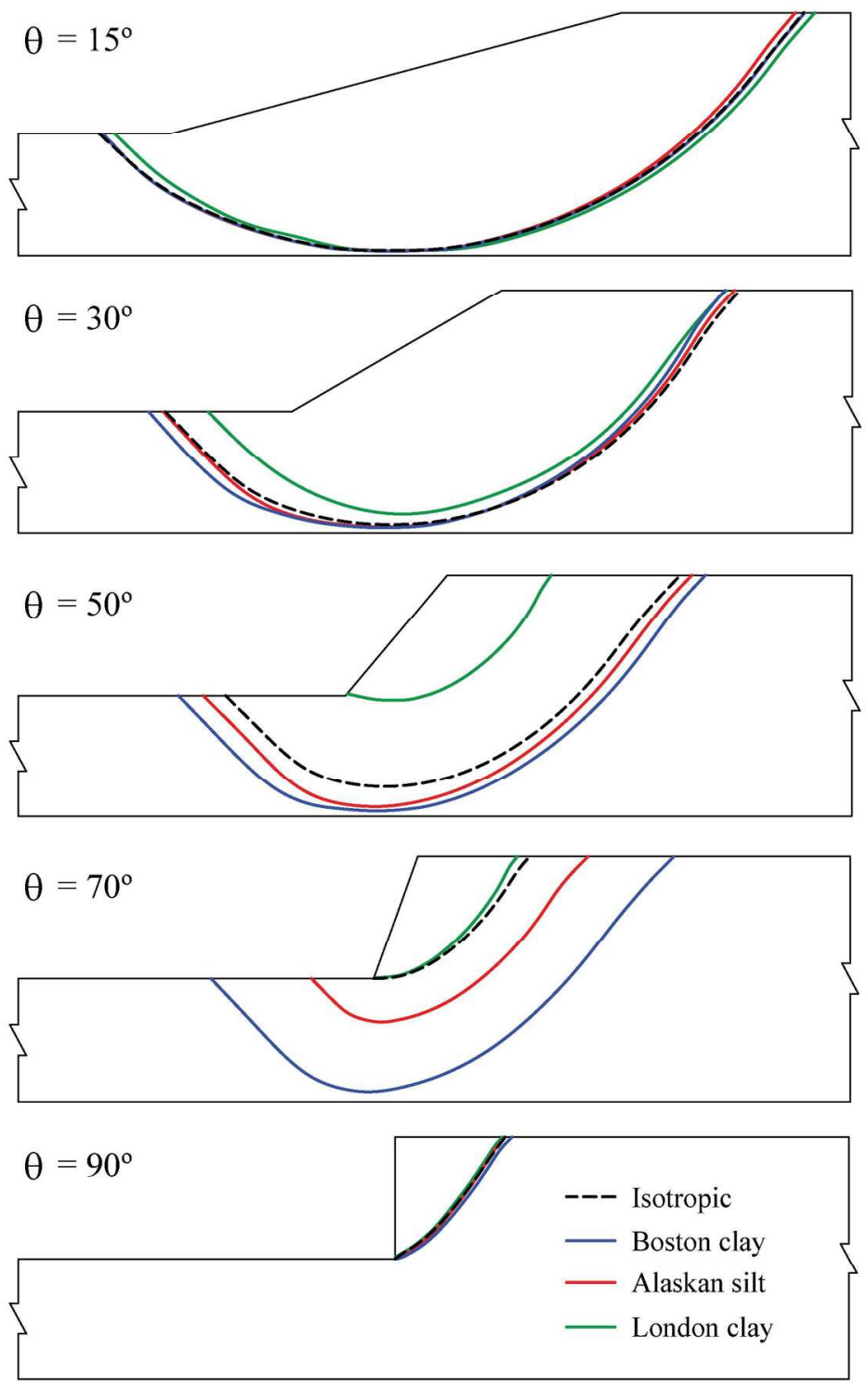

Figure 9

$145 \times 234 \mathrm{~mm}(300 \times 300$ DPI $)$ 


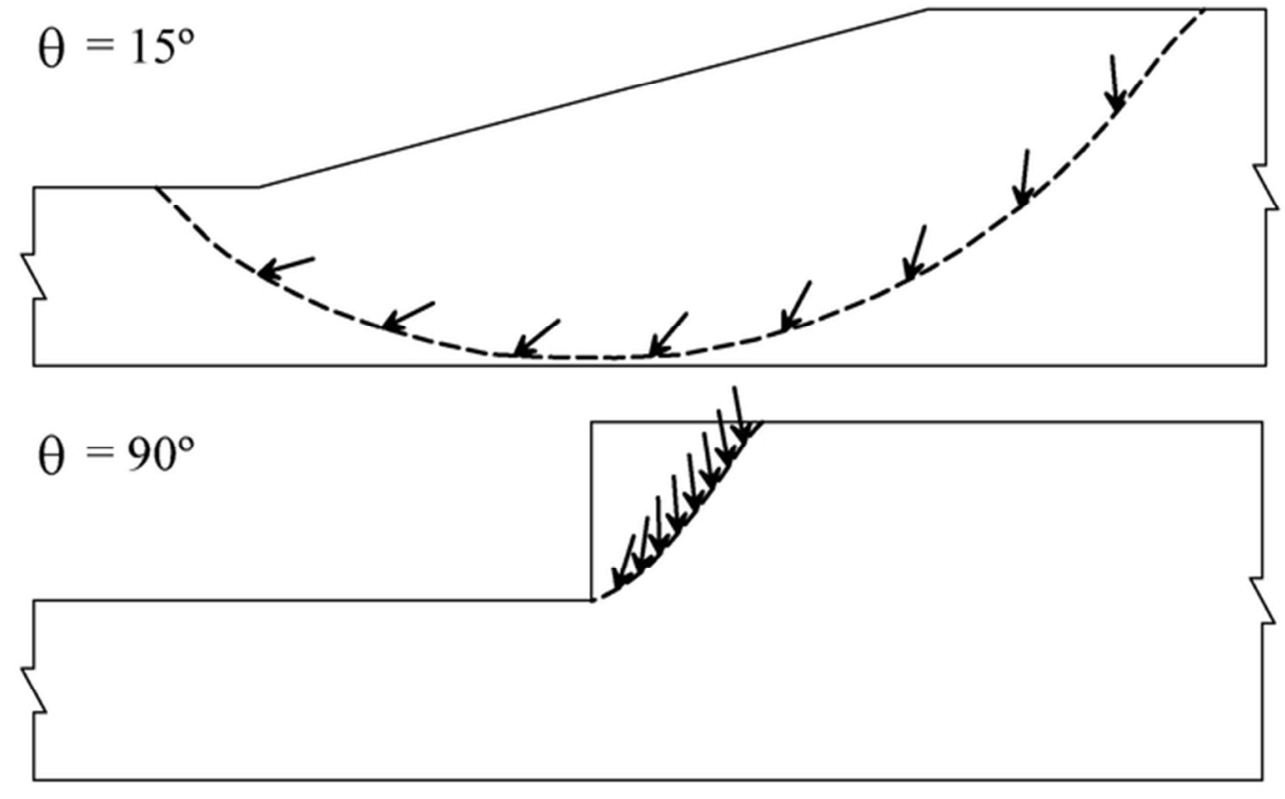

Figure 10

$58 \times 37 \mathrm{~mm}(300 \times 300$ DPI $)$ 


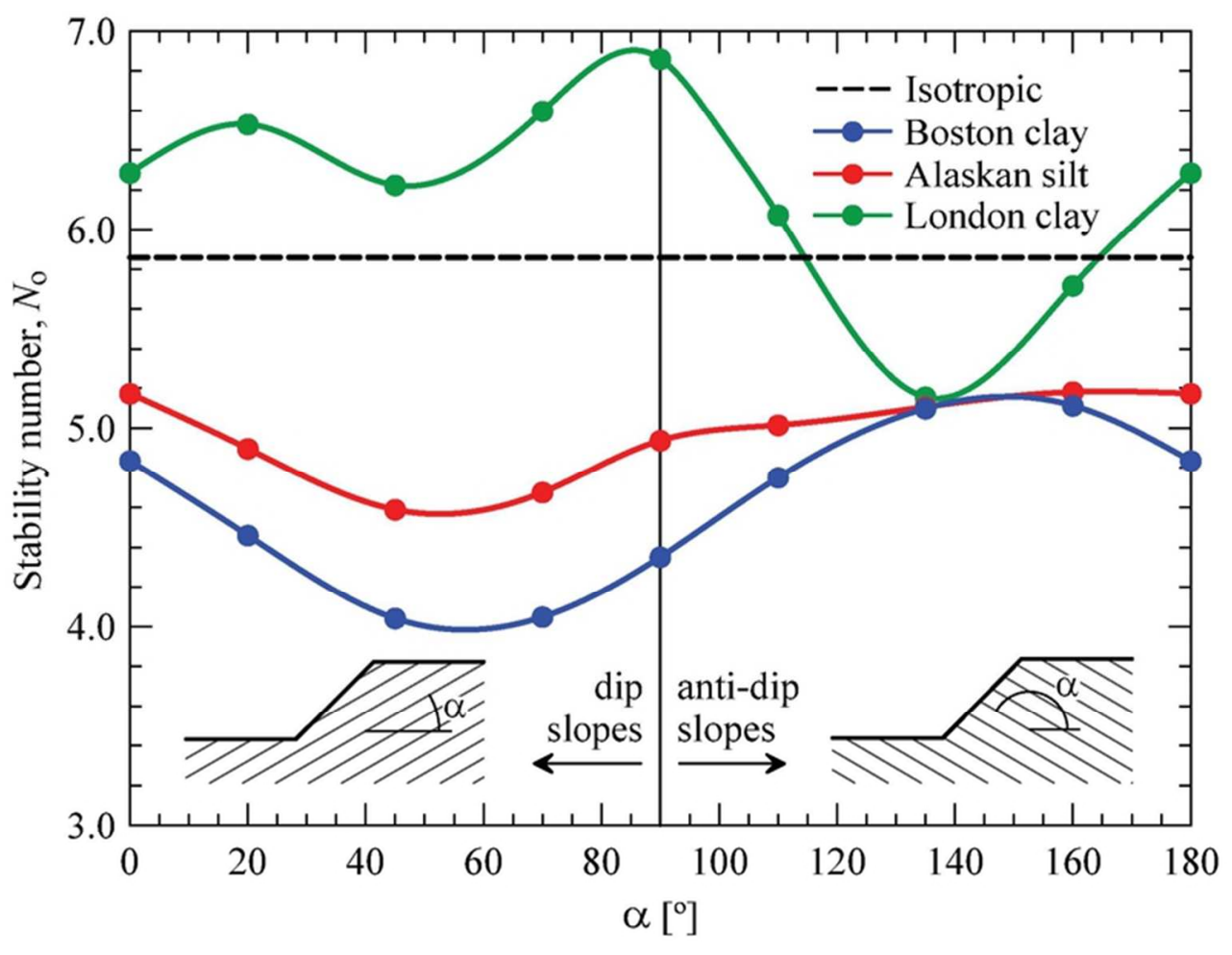

Figure 11

$69 \times 52 \mathrm{~mm}(300 \times 300$ DPI $)$ 

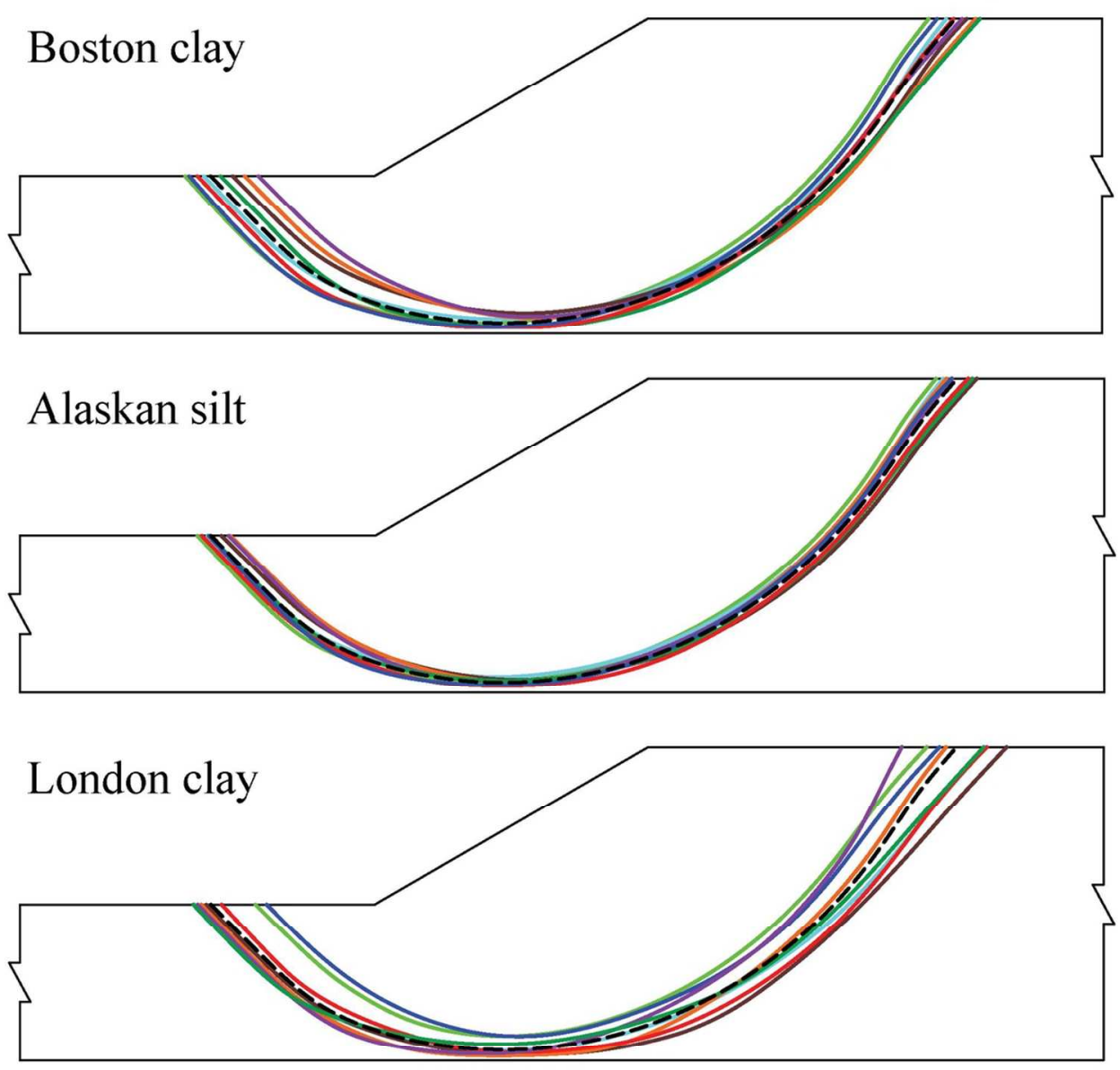

$$
\begin{array}{rlrl}
\theta=30^{\circ} & -- \text { Isotropic } & -\alpha=45^{\circ}-\alpha=110^{\circ} \\
& -\alpha=0^{\circ} & -\alpha=70^{\circ}-\alpha=135^{\circ} \\
-\alpha=20^{\circ} & -\alpha=90^{\circ}-\alpha=160^{\circ}
\end{array}
$$

Figure 12

$101 \times 114 \mathrm{~mm}(300 \times 300$ DPI) 


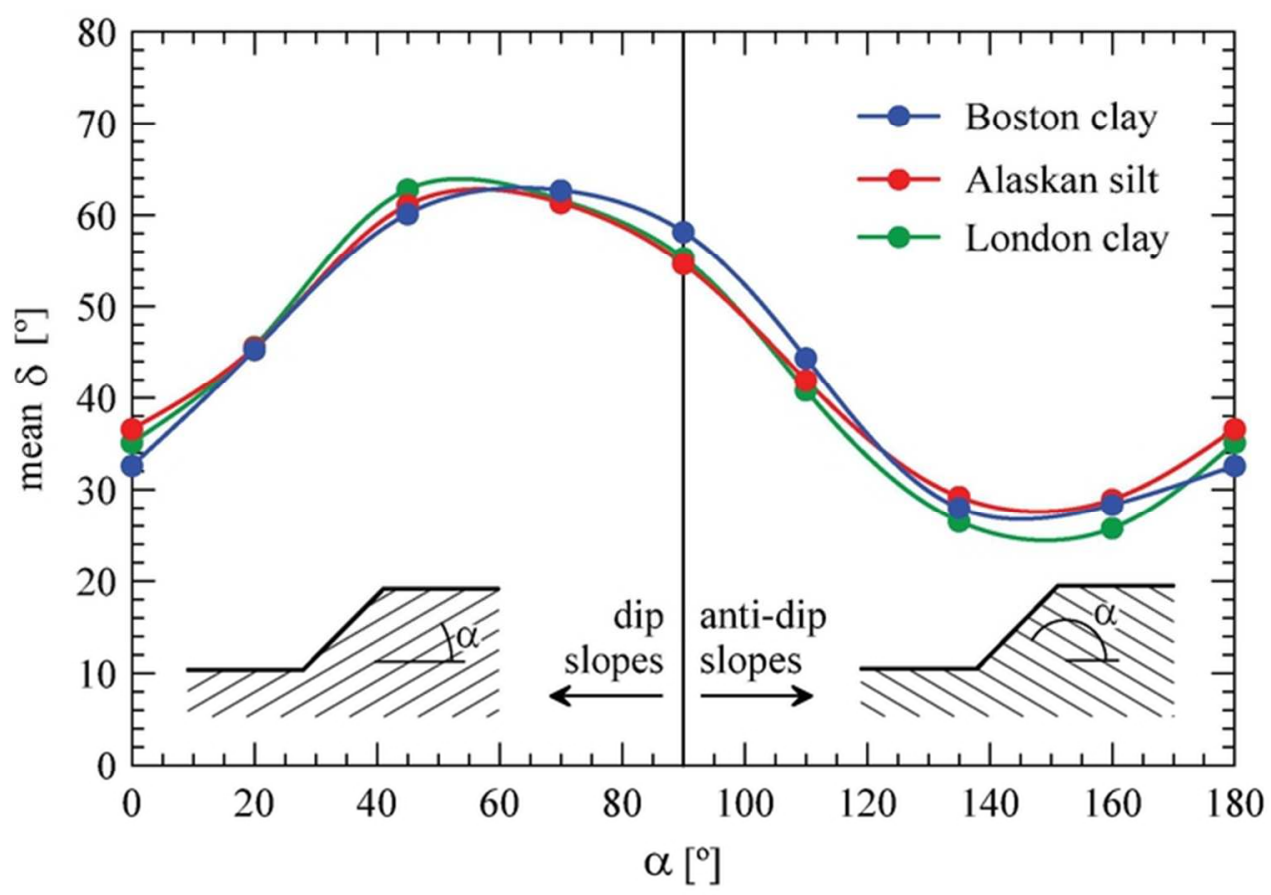

Figure 13

$62 \times 43 \mathrm{~mm}(300 \times 300$ DPI $)$ 


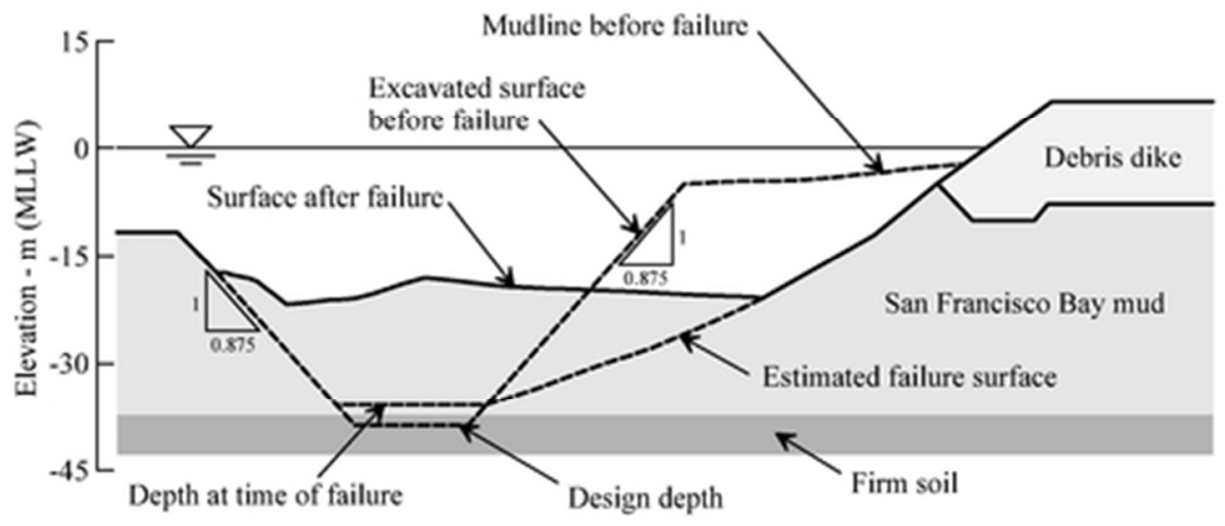

Figure 14

$40 \times 18 \mathrm{~mm}(300 \times 300 \mathrm{DPI})$ 
Figure 15

$32 \times 11 \mathrm{~mm}(300 \times 300$ DPI $)$ 


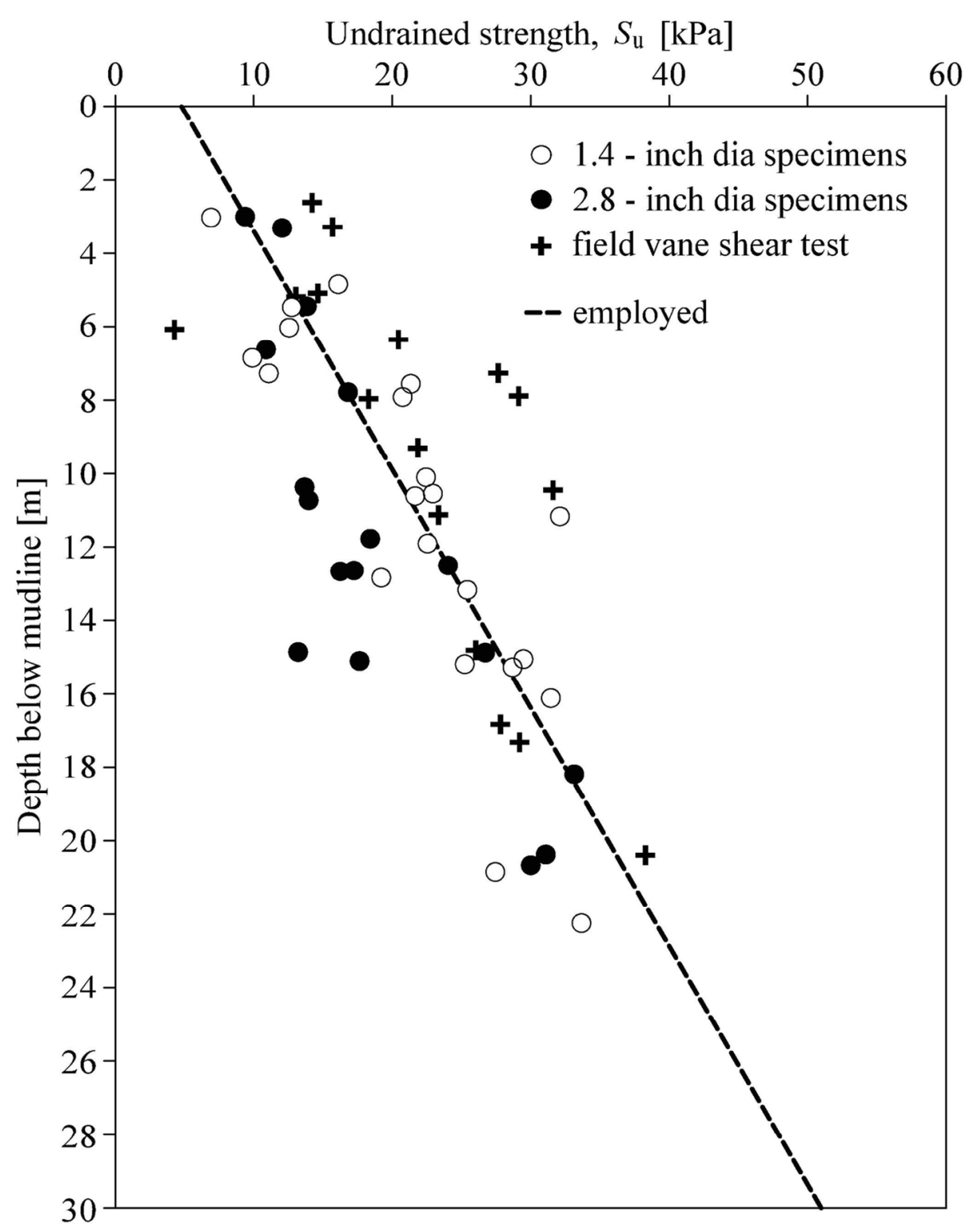

Figure 16

$114 \times 145 \mathrm{~mm}(300 \times 300 \mathrm{DPI})$ 


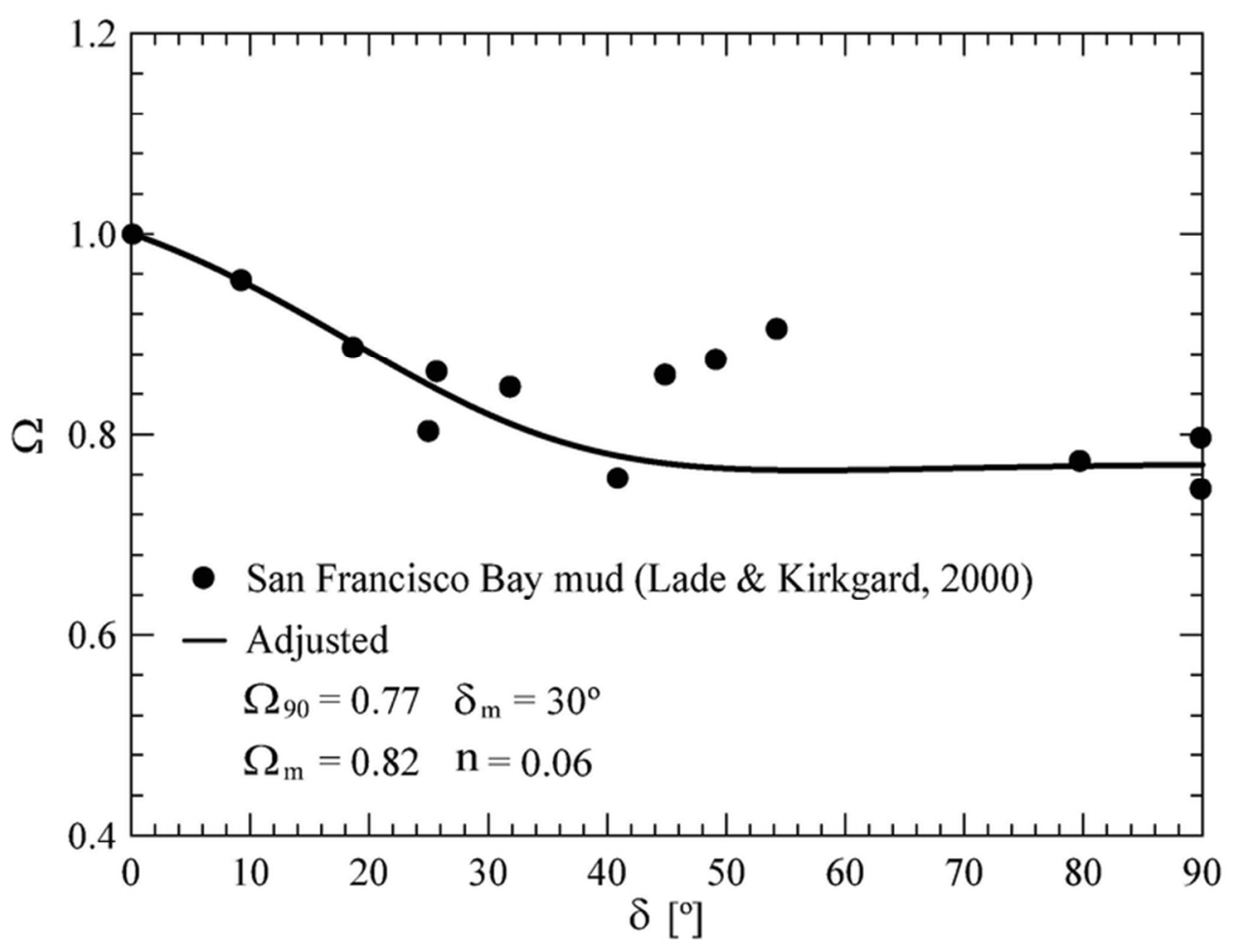

Figure 17

$69 \times 52 \mathrm{~mm}(300 \times 300 \mathrm{DPI})$ 

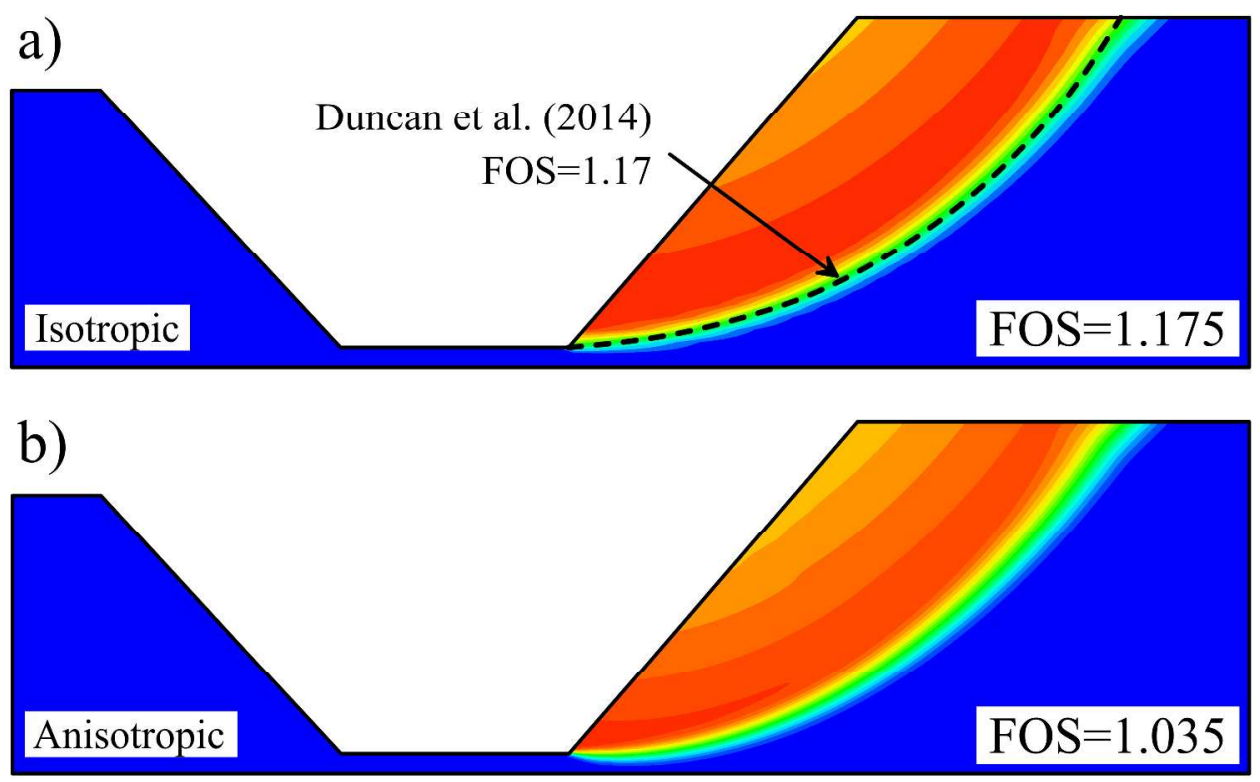

Figure 18

$1498 \times 962 \mathrm{~mm}(72 \times 72$ DPI $)$ 